\title{
ANIMOTS: UM EXERCÍCIO DE LEITURA DOS ANIMAIS
}

Eduardo Jorge

Mestrando UFMG

\section{RESUMO}

Este trabalho propõe uma leitura de $O$ animal que logo sou, de Jacques Derrida, suas relações com a literatura contemporânea e os animais, sobretudo no diálogo com o autor brasileiro Wilson Bueno.

\section{PALAVRAS-CHAVE}

Animais, Literatura, Jacques Derrida, Wilson Bueno

\section{O ANIMAL QUE NOS OLHA}

Em O animal que logo sou, Jacques Derrida nos oferece uma questão muito pertinente para pensarmos a literatura, em particular a poesia, em um estreito contato com o pensamento animal. Nas palavras do filósofo: “O pensamento do animal, se pensamento houver, cabe à poesia, eis aí uma tese, e é disso que a filosofia, por

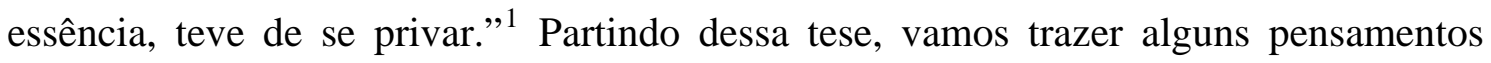
animais contidos na própria poesia. Neste ponto uma pergunta é fundamental. Se quem escreve o poema é o homem, como pode o animal pensar dentro do poema? E é neste ponto que queremos chegar, pois partindo de um devir-animal, conceito que devemos a Gilles Deleuze, onde o escritor afugenta o homem em si, o homem sem devir, e torna-se um feiticeiro justamente por habitar uma pele animal sem passar pelo plano da imitação, fazendo do próprio ato da escrita um devir. ${ }^{2}$ Assim, é dentro da escrita, do poema, que podemos pensar a crítica de Jacques Derrida a “O animal”: “é como se todos os viventes não humanos pudessem ser reagrupados no sentido comum desse lugar-comum”. ${ }^{3}$

\footnotetext{
${ }^{1}$ DERRIDA. O animal que logo sou, p. 22.

${ }^{2}$ DELEUZE; GUATARRI. Mil platôs. Capitalismo e esquizofrenia, p. 21.

${ }^{3}$ DERRIDA. O animal que logo sou, p. 64.
} 
Como se não houvesse “espaços infinitos” que separassem, pelo exemplo dado pelo próprio Derrida, “o protozoário do golfinho” e assim sucessivamente.

Ao contrário de filósofos como Descartes, Kant, Heidegger, que afirmaram que o animal é um ser privado de linguagem, Derrida parte por outro caminho onde a escrita tem um caráter privilegiado. Por isso também ele chega aos Animots, que, segundo o seu tradutor, Fábio Landa, pronuncia-se, em francês, exatamente da mesma maneira que Animaux, o plural de animal. "Mot” em francês quer dizer "palavra”. A constituição deste novo vocábulo pelo autor obedece ao mesmo procedimento de différence e différance efetuado por Derrida anteriormente, “que só se distinguem na escritura e não na pronúncia”. 4

São também com esses animots contidos no escritor que podemos ler alguns poemas/verbetes do brasileiro Wilson Bueno, em seus “bestiários” Manual de zoofilia (1997) e Jardim zoológico (1999), a partir das considerações de O animal que logo sou, de Derrida, que conclui: “Como acolher ou liberar tantos ANIMOTS em mim? (...) Isto teria dado ao mesmo tempo mais e menos que um bestiário.” 5

Assumir aqui uma leitura de Derrida como um exercício é portar na consciência um risco. Assim, também não deixamos de lado o célebre verso de Augusto de Campos tão carregado de sentido (ainda mais neste momento): poesia é risco. E que coisa é a poesia? Essa pergunta, já feita por Jacques Derrida, está distante de provocar uma resposta plausível, didática e que caiba dentro da letra $P$ de um dicionário ou na circularidade permissível da entrada de uma enciclopédia. Primeiro, porque Derrida nos pede para renunciar ao saber, saber esquecer o saber. Renunciar ao saber: existe algo que nos aproxime mais do animal? E aqui é interessante pensar na desarticulação de um discurso que torna o homem animal.

Vale lembrar que o filósofo franco-argelino ao confessar uma dificuldade de reprimir um movimento de pudor, uma vergonha de ter vergonha, desenvolve todo o seu ensaio diante do seguinte momento singular: Contra o mal-estar que pode haver em encontrar-se nu, o sexo exposto, nu diante de um gato que nos observa sem se mexer, apenas para ver. ${ }^{6}$ Portanto, é na potência do olhar de um animal (o gato) que Derrida vai pensar “que animal? O outro”. Essa incitação provocada por Derrida é muito bem

\footnotetext{
${ }^{4}$ Nota do tradutor em: DERRIDA. O animal que logo sou, p. 70.

${ }^{5}$ DERRIDA $O$ animal que logo sou, p. 70.

${ }^{6}$ DERRIDA $O$ animal que logo sou, p. 15.
} 
colocada no plano da escrita pelo escritor brasileiro Wilson Bueno. O escritor é capaz de renunciar a um saber humano para entrar na pele do animal. E como se o escritor também estivesse nu diante do felino a partir deste fragmento de seu Manual de zoofilia:

Notar deles como os dois olhos se acendem no escuro e o jeito como que ondulam invisíveis. Estão sempre perguntando desde sua íris-deespelhos. O mistério de que nada digam, só perguntem, é o que intriga e faz de um gato, mais que um dicionário novo, uma girafa, muito mais que uma tartaruga no cio. ${ }^{7}$

A sutileza captada por Wilson Bueno do sentir-se observado pelo gato, por esse outro, é o que o torna próximo da leitura de $O$ animal que logo sou. É o ato da própria humanidade desnudada diante da aparição do olhar de um ser cuja natureza não possui nudez. Para reforçar isso no texto, o animal não está nu porque ele é nu. ${ }^{8}$ Pelo contrário, o ato da humanidade desnudada implica uma lista que vai além do vestuário. Uma lista pensada por Derrida, de próprios do homem, cuja vestimenta seria apenas um destes próprios, onde se inclui a palavra, a razão, o logos, a história, o rir, o luto, a sepultura, o dom etc. ${ }^{9}$ Enfim, uma lista com um número infinito de conceitos, a começar pelo conceito de conceito. ${ }^{10}$ E voltando ao gato:

Se digo "é um gato real" que me vê nu, é para assinalar sua insubstituível singularidade. Quando ele responde ao seu nome (seja lá o que queira dizer "responder", e esta será pois nossa questão), ele não o faz como um exemplar da espécie "gato", ainda menos de um gênero ou de um reino "animal”. É verdade que eu o identifico como um gato ou uma gata. Porém, antes mesmo dessa identificação, ele vem a mim como este vivente insubstituível que entra um dia no meu espaço, nesse lugar onde ele pôde me encontrar, me ver, e até me ver nu. ${ }^{11}$

Há muito tempo, pode-se dizer que o animal nos olha? É essa a pergunta de Derrida. Mas, que animal? Insiste. O outro. ${ }^{12}$ Esse é um olhar cruzado por milênios. E a partir de um “próprio do homem”, a história, observa-se desde a cena da origem bíblica até as mais contemporâneas experiências genéticas que o olhar do homem a esses seres

\footnotetext{
${ }^{7}$ BUENO. Manual de zoofilia, p. 19.

${ }^{8}$ DERRIDA. O animal que logo sou, p. 17.

${ }^{9}$ DERRIDA. O animal que logo sou, p. 17.

${ }^{10}$ DERRIDA. O animal que logo sou, p. 17.

${ }^{11}$ DERRIDA. O animal que logo sou, p. 26.

${ }^{12}$ DERRIDA. O animal que logo sou, p. 15.
} 
pobres de mundo (para mencionar uma leitura de Martin Heidegger ${ }^{13}$ ) é um olhar que demarca bem um propósito dentro dos limites do humano. É com esta consciência diante do olhar do outro que vai existir um limite do humano colocado por Derrida:

Como todo olhar sem fundo, como os olhos do outro, esse olhar dito "animal" me dá a ver o limite abissal do humano: o inumano ou o ahumano, os fins do homem, ou seja, a passagem das fronteiras a partir da qual o homem ousa se anunciar a si mesmo, chamando-se assim pelo nome que ele acredita se dar. ${ }^{14}$

Assim, a crítica de Derrida direcionada a Descartes, Kant, Heidegger, Lacan e Levinas é que eles viam o animal como uma coisa vista que não vê, fazendo dos animais um teorema. Aniquilando, para usar um termo caro a Walter Benjamin, com a experiência do animal que vê, que tanto toca o filósofo franco-argelino. ${ }^{15}$

\section{HOMENS E ANIMAIS: OS LIMITES ABISSAIS DO OUTRO}

Essa configuração de um poder vivente da linguagem "humana”, seu gesto anímico trava estabelece o limite do animal como o "completamente outro”, ou seja, a designação e a exigência de resposta a um chamamento. ${ }^{16} \mathrm{E}$ ainda dentro deste “completamente outro” chamado animal, por exemplo, temos o gato. Surge o gesto anímico do poder que pode se desdobrar em inúmeros exemplos tais como esse completamente outro chamado animal, por exemplo, louco. Ou, dentro de uma leitura do escritor sul-africano J. M. Coetzee, em A vida dos animais, em que se pode ouvir a voz de Elisabeth Costello proferir, esse completamente outro chamado animal, por exemplo, judeu, do qual Coetzee toca no debate desta instituição de poder nomear um “completamente outro" para perseguir. E Coetzee ainda se prolonga mais, por intermédio da voz de sua personagem Elisabeth Costello ao comparar a matança de bois ao holocausto. Fato que é considerado um desrespeito à memória judaica do professor

\footnotetext{
${ }^{13}$ O fio que conduz a exposição de Heidegger está constituído por uma tese tripla: “a pedra é sem mundo [weltlos], o animal é pobre de mundo [weltarm], o homem é formador de mundo [weltbildend] (AGAMBEN. Lo abierto. El hombre y el animal, p. 95).

${ }^{14}$ DERRIDA. O animal que logo sou, p. 31.

${ }^{15}$ DERRIDA. O animal que logo sou, p. 33.

${ }^{16}$ DERRIDA. O animal que logo sou, p. 31.
} 
Abraham Stern, que assiste à palestra da escritora-personagem. ${ }^{17}$ E Derrida alimenta a discussão, falando por via da experiência da compaixão:

Como se, por exemplo, em lugar de jogar um povo nos fornos crematórios e nas câmaras de gás, os médicos ou os geneticistas (por exemplo, nazistas) tivessem decidido organizar por inseminação artificial a superprodução e supergeração de judeus, de ciganos e de homossexuais que, cada vez mais numerosos e mais nutridos, tivessem sido destinados, em um número sempre crescente, ao mesmo inferno, o da experimentação genética imposta, o da exterminação pelo gás ou pelo fogo. Nos mesmos abatedouros. ${ }^{18}$

A carta de Abraham Stern a Elisabeth Costello, dentro de $A$ vida dos animais, entra como um elemento a mais para a discussão sobre os limites entre o homem e o animal, onde bois não se comparam com judeus. Atualizando esse limite para o bemestar humano, matar bois é apenas uma violência no sentido mais neutro do ponto de vista moral. $^{19}$

Para sair um pouco da analogia com o holocausto, a loucura levou a outra aproximação do homem com o animal. Basta pensar na Paris da Belle Époque nos fins do século XIX e um Hospital chamado Salpêtrière, onde uma população de quatro mil mulheres (incuráveis ou loucas) vivia sua sorte. Michel Foucault na História da loucura trata bem desta questão do louco, este Outro vivendo como um animal. Assim, a relação entre asilos e zoológicos tem um desígnio carcerário comum para encerrar ali uma animalidade. Foucault, ao citar Coguel, deixa claro este modelo de animalidade (de jaula e zoológico no Salpêtrière no fim do século 18:

\footnotetext{
${ }^{17}$ E aqui vale mencionar a carta escrita pelo personagem-professor: "Prezada senhora Costello, Perdoe não ter comparecido ao jantar de ontem à noite. Li seus livros e sei que é uma pessoa séria, portanto acredito que devo levar a sério o que disse em sua palestra. Parece-me que no centro de sua palestra estava a questão de partilhar o pão. Se nos recusamos a partilhar o pão com os carrascos de Auschwitz, podemos continuar partilhando o pão com os abatedores de animais? A senhora se apropriou indevidamente da conhecida comparação entre os judeus assassinados na Europa e o gado abatido. Os judeus morreram como gado, portanto o gado morre como os judeus, diz a senhora. Trata-se de um jogo de palavras que não posso aceitar. A senhora se equivoca em relação à natureza da semelhança; diria até que se equivoca voluntariamente, a ponto de se tornar blasfema. O homem é feito à imagem de deus, mas Deus não é semelhante ao homem. Se os judeus são tratados como gado, não se pode concluir que o gado é tratado como os judeus. Essa inversão insulta a memória dos mortos. Além disso, trata os horrores dos campos de forma rasa. Perdoe a minha franqueza. A senhora disse que é velha demais para perder tempo com frivolidades. O mesmo vale para mim. Atenciosamente, Abraham Stern” (COETZEE. A vida dos animais, p. 59).

${ }^{18}$ DERRIDA. O animal que logo sou, p. 52.

${ }^{19}$ DERRIDA. O animal que logo sou, p. 51.
} 
As loucas acometidas por um acesso de raiva são acorrentadas como cachorros à porta de suas celas e separadas das guardiãs e dos visitantes por um comprido corredor defendido por uma grade de ferro; através dessa grade é que lhes entregam comida e palha, sobre o qual dormem; por meio de ancinhos, retira-se parte das imundícies que as cercam. ${ }^{20}$

Foucault explica que a animalidade na idade clássica perdeu seu indício de além da vida medieval e agora figura-se como a loucura do homem encerrando ele em si mesmo em um estado natural. Nas palavras de Foucault, a animalidade despoja o que há de humano no homem, chegando a estabelecê-lo no grau zero de sua própria natureza. Mesmo assim, essa animalidade chegava a protegê-lo contra o que poderia existir de frágil, precário e doentio no e do próprio homem: ${ }^{21}$

A solidez animal da loucura, e essa espessura que ela toma emprestado do mundo cego do animal, endurece o louco contra a fome, o calor, o frio e a dor. É notório, até o final do século XVIII que os loucos podem suportar indefinidamente as misérias da existência. Inútil protegê-los: não é necessário nem cobri-los, nem aquecê-los. ${ }^{22}$

Como um animal, podemos pensar essa expressão como um dispositivo pertencente à língua? O que significa como um animal? Sem dúvida existe uma carga de sofrimento, de maus-tratos ou um comportamento que não cabe na lógica estritamente humana e civilizada. Mas é diante do sofrimento animal que Jacques Derrida retoma uma pergunta:

“Eles podem sofrer?” consiste em se perguntar: "Eles podem não poder?”. E o que dizer desse não-poder? Da vulnerabilidade sentida a partir desse não-poder? Qual é este não-poder no âmago do poder? Qual é a quantidade ou a modalidade desse não-poder? O que levar em consideração? Que direito conferir-lhe? Em que isso nos concerne? Poder sofrer não é mais um poder, é uma possibilidade sem poder, uma possibilidade do impossível. Aí reside, como a maneira mais radical de pensar a finitude que compartilhamos com os animais, a mortalidade que pertence à finitude propriamente dita da vida, à experiência da compaixão, à possibilidade de compartilhar a possibilidade desse não-poder, a possibilidade dessa impossibilidade, a angústia dessa vulnerabilidade e a vulnerabilidade dessa angústia. ${ }^{23}$

\footnotetext{
${ }^{20}$ FOUCAULT. História da loucura, p. 150.

${ }^{21}$ FOUCAULT. História da loucura, p. 151.

${ }^{22}$ FOUCAULT. História da loucura, p. 151.

${ }^{23}$ DERRIDA. Che cos’è la poesia?, p. 55.
} 
É diante de uma pergunta desta natureza, deste “poder não poder” que mais uma vez a experiência da compaixão é trazida à tona, ou seja, essa vergonha de ter vergonha quando se está desnudado diante de um olhar de um gato. Como essa sujeição desde Adão, sozinho no universo e observado por Deus, nomeando os animais, sujeitando-os ao silêncio pelo dom da palavra humana.

Aqui existe uma questão de suma importância que Derrida se coloca: o homem como autor dos animais. Autor pelo gesto adâmico de nomear cada um dos animais e autor no sentido de estabelecer sua autoridade diante de sujeitar os animais. E o curioso é perceber que justamente uma serpente (esse completamente outro) fará o homem sentir-se nu e com vergonha. Então, pela história bíblica, sabemos que foi a serpente que deu ao homem a vergonha. Foi um animal que o deixou nu. E não à toa, pelo viés de fábulas e relatos míticos, que o homem tentará recuperar sua dignidade banindo a serpente. ${ }^{24}$ Voltando à sujeição deste outro, como se o olhar do gato lembrasse tudo, Derrida comenta:

Há muito tempo, é como se o gato lembrasse, como se ele me lembrasse, sem dizer uma só palavra, o relato terrível da Gênese. Quem nasceu primeiro, antes dos nomes? Quem viu chegar o outro em seu território, há muito tempo? Quem terá sido o primeiro ocupante, e portanto, o senhor? O sujeito? Quem continua, há muito tempo, sendo o déspota? ${ }^{25}$

Então como não pensar essa questão dentro dos estudos culturais, em que geralmente a peça de William Shakespeare, A tempestade, se tornou uma metáfora culturalista? Calibán, o monstro da ilha, é sujeito a Próspero, duque de Milão que perdeu seu trono e exerce seus poderes na ilha. Essa sujeição também infra-espécie: o dom da palavra, do logos, sujeita o outro, acontece dentro de tantos outros lugares.

E este alogon por natureza, o animal que encontrou diante de tantos pensadores a justificativa até de suas privações ao gesto adâmico, mas que passa também por uma relação homem-animal ainda na Antiguidade, nas hacatombes homéricas (o sacrifícios dos bois) e suas metáforas, além da caça, da pesca, domesticação, adestramento,

${ }^{24}$ E aqui, Derrida dá um golpe certeiro na antropomorfização dos animais pelo homem, criticando a fábula: "Seria preciso sobretudo evitar a fábula. A afabulação, conhecemos sua história, permanece um amansamento antropomórfico, um assujeitamento moralizador, uma domesticação. Sempre um discurso do homem; sobre o homem; efetivamente sobre a animalidade do homem, mas para o homem, e no homem. (DERRIDA. O animal que logo sou, p. 70). A fábula é, portanto, apenas mais uma forma humana de explorar os animais.

${ }^{25}$ DERRIDA. O animal que logo sou, p. 39. 
exploração de energia animal para o transporte e o trabalho de tração até o cão de guarda, o abate artesanal e a experimentação animal. ${ }^{26}$ É com uma desconfiança diante da linguagem e de sua pseudo-evidência, que o homem chama de seu mundo, seu saber, sua história e sua técnica, que Derrida afronta os sinais prévios dessa relação homemanimal: o animal (alogon) se encontra, segundo Heidegger, privado de acesso, em sua abertura mesma, ao ser do ente enquanto tal, ao ser tal, ao "enquanto tal” do que é. A tristeza, o luto, a melancolia da natureza ou da animalidade nasceriam assim, segundo Benjamin, desse mutismo, é certo, mas também, por isso mesmo, deste ferimento sem nome: ter recebido o nome. Ao se encontrar privado de linguagem, perde-se o poder de nomear, de se nomear, em verdade de responder em seu nome. (Como se o homem não recebesse também seu nome e seus nomes!) ${ }^{27}$

Por outro lado, Georges Bataille, em um de seus verbetes-críticos chamado metamorfose, que escreveu para a revista que editava chamada Documments, vai tratar o homem como uma prisão de aparência burocrática. ${ }^{28}$ Lendo esse verbete após a leitura de $O$ animal que logo sou, vamos observando como o escritor tratou destes próprios do homem

\begin{abstract}
Animais selvagens. Com respeito aos animais selvagens, os sentimentos equívocos dos seres humanos talvez sejam mais irrisórios do que em qualquer outro caso. Há a dignidade humana (na aparência, acima de qualquer suspeita) mas não será preciso irmos ao jardim zoológico: por exemplo, quando os animais vêem surgir a multidão de criancinhas seguidas por papás-homens e mamãs-mulheres. Apesar das aparências, o hábito não consegue impedir um homem de saber que mente como um cão quando fala de dignidade humana no meio dos animais. Porque em presença de seres ilegais e profundamente livres (os únicos verdadeiramente outlaws), a mais equívoca das invejas ainda leva a melhor sobre uma estúpida sensação de superioridade prática (inveja que se manifesta nos selvagens sob a forma de totem que se dissimula, de um modo cômico, nos chapéus com penas das nossas avós de família). Com tantos animais no mundo só perdemos isto: a inocente crueldade, a monstruosidade opaca dos olhos que mal se diferencia de pequenas bolhas formadas à superfície da lama, o horror ligado à vida como uma árvore à luz. Restam os gabinetes, os bilhetes de identidade, uma vida de criados biliosos e, no entanto, sei lá que estridente loucura chega a parecer-se, durante certos desatinos, com a metamorfose.
\end{abstract}

Podemos definir a obsessão da metamorfose como uma violenta necessidade que aliás se confunde com cada uma das nossas necessidades animais, que arrastam um homem a afastar-se de repente dos gestos e das atitudes exigidas pela natureza humana: por exemplo,

\footnotetext{
${ }^{26}$ DERRIDA. O animal que logo sou, p. 50-51.

${ }^{27}$ DERRIDA. O animal que logo sou, p. 41.

${ }^{28}$ BATAILLE. A mutilação sacrificial e a orelha cortada de Van Gogh, p. 105.
} 
um homem no meio dos outros, num apartamento, deitar-se de barriga para baixo e começar a comer a comida do cão. Há, pois, em cada homem um animal fechado numa prisão como um forçado, e também há uma porta; se abrirmos essa porta, o animal corre para fora como o forçado que encontra a saída da prisão; e então, de um modo provisório, o homem cai morto e o animal comporta-se como um animal sem preocupação nenhuma de provocar admiração poética do morto. É neste sentido que se olha para um homem como uma prisão de aparência burocrática. ${ }^{29}$

Bataille, nesse verbete, toca em vários aspectos a leitura derridiana do animal. E deixa também claro que o abismo existente entre o homem e o animal, no pensamento de Derrida, pode ser menor, por conta de uma animalidade. Essa animalidade não se refere tão somente ao fato explicitado por Bataille de deitar para comer no chão a comida do cachorro, pois o comportamento humano está mimetizando o comportamento animal. E não é por mimesis e sim pelo devir que o homem minimiza essa distância.

Como em outro texto, $O$ que é a poesia?, Jacques Derrida discorre sobre a diferença entre um saber filosófico e um pensamento poético. ${ }^{30} \mathrm{E}$ esse texto ilumina as ideias de Derrida em $O$ animal que logo sou, que mais uma vez se aproxima de escritores como Clarice Lispector e Wilson Bueno, que praticam um exercício de “outridade” 31 para mencionar uma leitura derridiana muito bem pontuada por Maria Esther Maciel:

Dentro do repertório brasileiro, destaca-se ainda, num contexto bem mais contemporâneo, o escritor paranaense Wilson Bueno que, além de recriar antigos bestiários a partir de um enfoque cultural notadamente latino-americano, busca trazer para seus escritos, à feição de Clarice Lispector, “o it dos animais”. Isso, por ele ser também um escritor consciente de que, mais do que comparar os "mundos humanos" aos "mundos animais", cabe à literatura explorar a intensa complexidade de cada um deles. Principalmente em seus livros Jardim zoológico (1999) e Manual de zoofilia (1997), Bueno explora a passagem das fronteiras entre o humano e o inumano, num processo de identificação do sujeito poético com o que Derrida chama de "esse completamente outro" que é o animal. ${ }^{32}$

É com um devir-animal que Wilson Bueno vai compor esses livros citados por Maria Esther Maciel. Esse devir já busca uma aproximação de dois pensamentos: de Gilles Deleuze com Jacques Derrida. E aqui, Wilson Bueno será o ponto de encontro

\footnotetext{
${ }^{29}$ BATAILLE. A mutilação sacrificial e a orelha cortada de Van Gogh, p. 104-105.

${ }^{30}$ DERRIDA. O animal que logo sou, p. 22.

${ }^{31}$ MACIEL. Zoopoéticas contemporâneas, p. 200.

${ }^{32}$ MACIEL. Zoopoéticas contemporâneas, p. 201.
} 
entre o devir-animal e os animots. Aliás, podemos, até por entrelaçamento, arriscar dizer que os animots (de Derrida e, por conseguinte, de Wilson Bueno) decorrem deste devir. Como propunha Deleuze, ${ }^{33}$ "Se um escritor é um feiticeiro é porque escrever é um devir, escrever é atravessado por estranhos devires que não são devires-escritor, mas devires-rato, devires-inseto, devires-lobo, etc.” Essa singularidade alcançada por Deleuze é muito própria a Derrida, onde um invasor potencial se alojaria em um operador de escritura, de leitura, de interpretação: ${ }^{34}$

Mas, se posso notá-lo antecipando amplamente sobre o que se seguirá, seria um animal capaz de rasurar (portanto de apagar um rastro, disso que Lacan diz ser o animal incapaz). Esse quase-animal não teria mais que se referir ao ser como tal (disso que Heidegger dirá ser o animal incapaz), pois ele se daria conta da necessidade de rasurar o "ser". ${ }^{35}$

É desapontando os filósofos que os escritores dariam conta dessa necessidade de rasurar o ser. Wilson Bueno por retirar a aparência burocrática do homem ao desordenar uma escrita que cataloga em um manual os afetos pelos animais, no qual se incluem seres como as crianças: "Pequenos animais agarrados ao vício de existir ... se transform(a)m no acabado projeto de um ser humano, aí com a previsível catástrofe que já de ser sempre o selo de toda e qualquer utopia.” ${ }^{36}$.

\section{BIOS, ZOÉ}

Por fim, outra das hipóteses colocadas por Jacques Derrida: nós vivemos. Derrida problematiza o que chamamos ou poderíamos chamar tranquilamente de vida, essa experiência na qual se abalam os limites à passagem de fronteiras entre bios e zoé, biológico, zoológico e antropológico, como entre vida e morte, vida e técnica, vida e história etc. ${ }^{37}$ Entretanto Derrida hesita ao dizer que vivemos uma reviravolta histórica porque esse modelo (reviravolta) implica uma instantaneidade ainda presa a modelos genéticos, biológicos ou zoológicos. ${ }^{38}$

\footnotetext{
${ }^{33}$ MACIEL. Zoopoéticas contemporâneas, p. 21

${ }^{34}$ DERRIDA. O animal que logo sou, p. 74.

${ }^{35}$ DERRIDA. O animal que logo sou, p. 74

${ }^{36}$ BUENO. Manual de zoofilia, p. 41.

${ }^{37}$ DERRIDA. O animal que logo sou, p. 49.

${ }^{38}$ DERRIDA. O animal que logo sou, p. 49.
} 
É nesse ponto que é interessante voltar para $A$ vida dos animais, de J. M. Coetzee: "Você acredita mesmo, mãe, que aulas de poesia podem fechar matadouros?" Pergunta o filho de Elisabeth Costello, ao que ela responde: “Não”. Dentro dos "próprios do homem” o conceito de função é um dos que mais preciosos para a humanidade, que acaba sendo complementar a reviravolta questionada por Derrida. Como se não lembrássemos que a funcionalidade, o "isto serve para" ou o sintoma de mudança também não estivessem neste próprio e não representasse também uma previsibilidade. E é isso que torna o pensamento de Jacques Derrida e a literatura algo interessante: desarticular verdades prontas e preparadas antes mesmo do nascimento de qualquer um de nós.

\section{ABSTRACT}

This article proposes a reading of $O$ animal que logo sou (2002), by Jacques Derrida, of its relations to contemporary literature and the animals, and above all, it proposes a dialogue with a Brazilian author, Wilson Bueno.

\section{KEYWORDS}

Animals, Literature, Jacques Derrida, Wilson Bueno

\section{REFERÊNCIAS}

AGAMBEN, Giorgio. Lo abierto. El hombre y el animal. Trad. Flavia Costa y Edgardo Castro. Buenos Aires: Adriana Hidalgo, 2006.

BATAILLE, Georges. A mutilação sacrificial e a orelha cortada de Van Gogh. Trad. Carlos Valente. Lisboa: Hiena, 1994.

BUENO, Wilson. Manual de zoofilia. 2. ed. Ponta Grossa: Ed. UEPG, 1997.

BUENO, Wilson. Jardim zoológico. São Paulo: Iluminuras, 1999.

DELEUZE, Gilles; GUATARI, Felix. Mil platôs. Capitalismo e esquizofrenia. Trad. Suely Rolnik. São Paulo: Ed. 34, 1995. v. 4.

DERRIDA, Jacques. Che cos'è la poesia? Trad. Tatiana Rios e Marcos Siscar. In: . Points de suspension. Paris: Galilée, 1992.

DELEUZE, Gilles; GUATARI, Felix. A literatura e a vida. In: . Crítica e clínica.

Trad. Peter Pál Pelbart. São Paulo. Ed. 34, 1997. 
DERRIDA, Jacques. O animal que logo sou. Trad. Fábio Landa. São Paulo: Unesp, 2002.

DIDI-HUBERMAN, Georges. La invención de la histeria. Charcot y la iconografia fotográfica de la Salpêtrière. Trad. Tania Arias e Rafael Jackson. Madrid: Cátedra, 2007.

COETZEE, J. M. A vida dos animais. Trad. José Rubens Siqueira. São Paulo: Companhia das Letras, 2003.

FOUCAULT, Michel. História da loucura. Trad. Teixeira Coelho. São Paulo: Perspectiva, 2005.

MACIEL, Maria Esther. Zoopoéticas contemporâneas. Remate de Males, Campinas, v. 27, n. 2, p. 197-206, jul./dez. 2007.

YELIN, Julieta Rebeca. Nuevos imaginarios, nuevas representaciones. Algunas claves de lectura para los bestiarios latinoamericanos contemporáneos. Nueva York: LLJournal, v. 3, n. 1, 2008. Disponível em: <http: ojs.gc.cuny.edu/index.php/lljournal/ article/view/302/328>. Acesso em: 14 set. 2008. 